\title{
Can We Constrain CMIP5 Rainfall Projections in the Tropical Pacific Based on Surface Warming Patterns?*
}

\author{
Michael R. Grose, Jonas Bhend, And Sugata NARSEY \\ CSIRO Climate Adaptation National Research Flagship, CSIRO Marine and Atmospheric Research, Aspendale, \\ Victoria, Australia
}

Alex Sen Gupta

Climate Change Research Centre, University of New South Wales, Kensington, New South Wales, Australia

JOSEPHINE R. BROWN

Centre for Australian Weather and Climate Research, Bureau of Meteorology, Melbourne, Victoria, Australia

(Manuscript received 10 March 2014, in final form 3 September 2014)

\begin{abstract}
Climate warming has large implications for rainfall patterns, and identifying the most plausible pattern of rainfall change over the next century among various model projections would be valuable for future planning. The spatial pattern of projected sea surface temperature change has a key influence on rainfall changes in the tropical Pacific Ocean. Here it is shown that simple indices of the size of the equatorial peak in the spatial pattern of warming and to a lesser extent the hemispheric asymmetry in warming are useful for classifying the surface temperature change in different models from phase 5 of the Coupled Model Intercomparison Project (CMIP5). Models with a more pronounced equatorial warming show a fairly distinct rainfall response compared to those with more uniform warming, including a greater "warmer-get-wetter" or dynamical response, whereby rainfall increases follow the surface warming anomaly. Models with a more uniform warming pattern project a smaller rainfall increase at the equator and a rainfall increase in the southern tropical Pacific, a pattern that is distinct from the multimodel mean of CMIP5. Thus, the magnitude of enhanced equatorial warming and to some extent the hemispheric asymmetry in warming provides a useful framework for constraining rainfall projections. While there is not a simple emergent constraint for enhanced equatorial warming in models in terms of past trends or bias in the current climate, further understanding of the various feedbacks involved in these features could lead to a useful constraint of rainfall for the Pacific region.
\end{abstract}

\section{Introduction}

Changes to rainfall patterns in a warming climate have major impacts on water security for many Pacific island nations, with implications for many sectors including agriculture, infrastructure, and human health. Reliable

\footnotetext{
* Supplemental information related to this paper is available at the Journals Online website: http://dx.doi.org/10.1175/JCLI-D-1400190.s1.

Corresponding author address: Michael R. Grose, CSIRO Marine and Atmospheric Research, 107-121 Station St., Aspendale VIC 3195, Australia.

E-mail: michael.grose@csiro.au
}

and island-specific rainfall projections would be very useful for regional adaptation planning. Global climate models (GCMs) are our primary tool for making climate projections, with phase 5 of the Coupled Model Intercomparison Project (CMIP5) constituting the latest coordinated set of GCM simulations of historical and future climate (Moss et al. 2010; Taylor et al. 2012). However, there is still large uncertainty in rainfall projections for the tropical Pacific Ocean, as reflected in the large range of rainfall projections between different CMIP5 models, including many regions where the sign of change is uncertain (IPCC 2013). Any capacity to constrain projections would therefore be useful.

Most CMIP5 models have systematic biases in the western tropical Pacific (Li and Xie 2013; Grose et al. 
2014), and an evaluation of the biases in models could potentially be used as a basis to weight models or reject particularly poor models and thereby constrain projections. However, the spatial scale of evaluation is important and different frameworks to evaluate models suggest different weightings (Masson and Knutti 2011). For some purposes and regions, a metric of a single regional feature using a single variable may be suitable to select the most appropriate models and reduce spread in projections (Schaller et al. 2011). However, constraints based on model skill are only possible where there is a connection between the biases in the current climate and future change (i.e., the models with lower biases must have a reduced range compared to the entire ensemble). In many cases, the models with lower biases do not show a reduced spread, and good performance in the present does not guarantee skill in projecting the future (Jun et al. 2008; Reifen and Toumi 2009; Schaller et al. 2011). Where there is an obvious physical relationship between a property in the current climate and some aspect of Earth system sensitivity across an ensemble of models, this "emergent constraint" may be useful to understand and possibly constrain projections (Whetton et al. 2007; Flato et al. 2013). For example, within an ensemble of models the strength of the snow-albedo feedback in the seasonal cycle of the current climate is strongly correlated with the feedback under future climate change (Hall and Qu 2006). Emergent constraints are a growing area of research with several other encouraging examples; see Flato et al. (2013) for more information. We use this concept to investigate potential constraints on rainfall projections in the tropical Pacific. We first examine the projected pattern of change of surface temperature over the tropical Pacific Ocean based on some simple indices of key features, and then analyze if this range of change may be related to a factor in the current climate. We use surface warming patterns since they play a key role in rainfall projections in the Pacific.

The thermodynamic influence of large-scale atmospheric warming on the hydrological cycle and circulation generally causes climatologically wet regions to become wetter and already dry areas to become drier, the so-called wet-get-wetter and dry-get-drier paradigm (Held and Soden 2006). This effect is linked to increases in atmospheric moisture and is associated with a slowdown of the overturning circulation and in particular the Walker circulation in the tropical Pacific (Vecchi et al. 2006). In addition to the thermodynamic effects, changes to surface temperature gradients and other dynamic influences also contribute to precipitation changes. In particular, changes in temperature gradients are conducive to a "warmer-get-wetter" response whereby tropical areas where surface temperature warms more than the regional mean tend to get wetter (Chou et al. 2009; Johnson and Xie 2010; Sobel and Camargo 2011; Xie et al. 2010; Widlansky et al. 2013). Since the upper troposphere is projected to warm nearly uniformly due to fast wave actions, regions of greater convective instability and therefore precipitation are largely determined by spatial variations in SST warming $(\triangle \mathrm{SST})$ and related low-level moisture change (Johnson and Xie 2010; Chadwick et al. 2014).

Previous studies have shown the combined contributions from the thermodynamic and dynamic influences in driving future rainfall change in the tropics, implying that the projected spatial pattern of $\Delta S S T$ is an important determinant of rainfall projections in the Pacific over the century (Vecchi and Soden 2007; Seager et al. 2010; Xie et al. 2010; Brown et al. 2012; Chadwick et al. 2013; Ma and Xie 2013; Widlansky et al. 2013; Chadwick et al. 2014). Indeed, the intermodel spread of $\Delta$ SST can explain a large fraction of the intermodel spread in the projected zonal mean tropical rainfall distribution in phase 3 of the Coupled Model Intercomparison Project (CMIP3) (Ma and Xie 2013). Change in tropical SST can be broken down into two components: the spatially uniform SST increase and the spatial deviation from spatial uniform warming. Model experiments that impose a spatially uniform increase in SST produce a largely wet-get-wetter precipitation response (Xie et al. 2010; Ma and Xie 2013). The spatially varying component of $\Delta$ SST produces changes in SST gradients, and therefore warmer-get-wetter-type responses (Xie et al. 2010; Ma and Xie 2013). Thus a wet-get-wetter response implies a spatial correlation between the precipitation response and the precipitation climatology, while a warmer-get-wetter response implies a spatial correlation between the precipitation response and $\Delta$ SST (Ma and Xie 2013).

In this study we are interested in regional climate projections for nations in the tropical Pacific Ocean. Three important spatial features of $\Delta$ SST in the tropical Pacific have been previously identified that are common to most model projections: 1) a "warming amplification" or enhanced equatorial response (EER) at the equator of the Pacific; 2) a hemispheric asymmetry of warming; and 3) a minimum in $\triangle$ SST in the southeast subtropics (Xie et al. 2010; Ma and Xie 2013).

The EER is projected by almost all models under a warming climate. Liu et al. (2005) found this enhanced equatorial warming to be distinct in space and time from the El Niño pattern and not related to a shift toward a more El Niño-dominated climate (i.e., is not related to increased frequency of amplitude of El Niño events). Various mechanisms and feedbacks influence the degree of enhanced warming at the equator. For example, 
temperature change is dependent on climatological evaporation, and there is a meridional minimum in evaporative damping on the equator (Liu et al. 2005; Xie et al. 2010). Ocean dynamics also contribute to the EER (DiNezio et al. 2009). The EER should be distinguished from a different but related SST warming pattern; the zonal gradient of equatorial Pacific warming. Processes are thought to play a role in modifying the zonal gradient of SST may also contribute to enhanced warming at the equator. The projected slowing of the Walker circulation leads to a reduction in wind speeds (Vecchi et al. 2006), and this leads to an increase in the eastern Pacific thermocline depth, creating a "thermocline feedback" (Vecchi and Soden 2007). Greater dynamical heating of the western equatorial Pacific compared to the east due to cloud cover feedbacks and evaporation balance is thought to produce a zonal gradient, but may also drive changes to currents and contribute to an EER (DiNezio et al. 2009). The cooling effect of the "ocean thermostat" (Clement et al. 1996) and the counter upwelling damping in the eastern Pacific (Liu 1998) contribute to a zonal gradient and so affect the overall SST warming pattern. There is a spread between models in the east-west gradient of SST change along the equator across CMIP3 (Liu et al. 2005) and CMIP5 (Brown et al. 2014; Brown et al. 2014, manuscript submitted to Deep-Sea Res.), and this affects the formation of an EER. Also, a study using a single model found that the development of an EER may be nonlinear in time, where warming at the equator results from a switch from initial warming of extratropical waters to then warming the tropics (Cai and Whetton 2000).

The EER is associated with a projected increase in convective mass flux over the equator in CMIP3 (Liu et al. 2005) and in 12 CMIP5 models examined by Chadwick et al. (2013), resulting in a warmer-getwetter-type precipitation response along the equator (Chou et al. 2009; Xie et al. 2010). Enhanced equatorial warming is central to a projected annual precipitation increase "anchored" to the equator in a warmer-getwetter pattern but this pattern marches back and forth across the equator with the seasons (Xie et al. 2010; Huang et al. 2013).

This study is concerned with centennial-scale trends in SST, as distinct from changes at shorter time scales. As mentioned above, the EER is distinct from the response at the equator during El Niño years. Also, there are warmer SSTs at the equator during positive phases of the interdecadal Pacific oscillation (IPO) associated with the enhanced global warming such as in the mid-1970s climate "shift," whereas conversely equatorial cooling is associated with a global warming "hiatus" decade such as in 1998-2012 (Meehl and Teng 2012; Kosaka and Xie 2013; England et al. 2014). However, these patterns have a spatial and seasonal signature that is distinct from the EER in the long-term trend.

Most models also project a hemispheric asymmetry in surface warming, with weaker surface warming in the Southern Hemisphere than the Northern Hemisphere tropics. This warming asymmetry is possibly linked to the difference in land-sea coverage in each hemisphere (Liu et al. 2005), asymmetries in wind changes, or the influence of the weak warming in the Southern Ocean on the South Pacific (Xie et al. 2010). Liu et al. (2005) describes the spread in the magnitude of this asymmetry across the CMIP3 models. An important component of the hemispheric asymmetry is the $\triangle$ SST minimum in the subtropical southeastern Pacific. This feature has been linked to a projected intensification of the southeast trade winds via a wind-evaporation-SST feedback (Timmermann et al. 2010; Xie et al. 2010).

Ma and Xie (2013) find that model differences in hemispheric asymmetry and EER in $\triangle$ SST explain 36\% of the intermodel variability in zonal-mean tropical precipitation in CMIP3, with similar results found in CMIP5. For any particular model, the pattern of projected $\triangle$ SST over the twenty-first century is determined by the changes to the relevant processes and feedbacks. However, the projection is also influenced by model biases. For example, the formation of an EER is related in part to zonal variations in mean state SST in the current climate (Xie et al. 2010). The equatorial cold tongue bias that exists in many GCMs means that there are biases in SST gradients that are likely to affect the pattern of SST change and development and strength of an EER. The cold tongue bias is a problem in almost all models and is related to errors in net surface heat flux, ocean heat advection and subsurface temperature structure, excessively zonal currents, and a weak Bjerknes feedback (Zheng et al. 2012). As such, estimating a reliable climate change signal in $\triangle$ SST is a challenge given the prevalence of model biases shared by many models.

Previous studies of Pacific precipitation response have been able to use single model experiments, coupled model runs from the 23 CMIP3 GCMs, and subsets of models from the emerging CMIP5 archive. The number of CMIP5 models used in the studies so far does not allow the examination of the intermodel range, relationships, and typologies over a large ensemble. For example, only 12 models were available to examine questions of convective mass flux and the presence of the wet-get-wetter influence in Chadwick et al. (2013), and 18 models were available to look at the seasonal response in Huang et al. (2013). As more models are added to CMIP5, the opportunity to examine intermodel differences increases, and this has the potential to 
TABLE 1. CMIP5 models used in this study, their transient climate response (from Flato et al. 2013), RMSE of the zonal mean SST compared to HadISST, and indices discussed in the paper over 1950-2005 and 2006-2100: the EER, HA, and SE indices.

\begin{tabular}{|c|c|c|c|c|c|c|c|c|}
\hline \multirow[b]{2}{*}{ Model } & \multirow{2}{*}{$\begin{array}{l}\text { Transient climate } \\
\text { response }\left({ }^{\circ} \mathrm{C}\right)\end{array}$} & \multirow{2}{*}{$\begin{array}{c}\text { Zonal SST } \\
\text { RMSE }\end{array}$} & \multicolumn{2}{|c|}{ EER index } & \multicolumn{2}{|c|}{ HA index } & \multicolumn{2}{|c|}{ SE index } \\
\hline & & & 1950-2005 & $2006-2100$ & 1950-2005 & $2006-2100$ & $1950-2005$ & $2006-2100$ \\
\hline ACCESS1.0 & 2.00 & 1.33 & 0.65 & 0.42 & -0.15 & 0.50 & 0.07 & 0.65 \\
\hline ACCESS1.3 & 1.70 & 0.95 & -0.73 & 0.43 & -0.06 & 0.55 & 0.89 & 0.74 \\
\hline BCC_CSM1.1 & 1.70 & 0.45 & 0.11 & 0.25 & 0.13 & 0.22 & 1.04 & 0.84 \\
\hline BCC_CSM1.1(m) & 2.10 & 0.80 & 0.01 & 0.29 & 0.29 & 0.27 & 1.32 & 0.63 \\
\hline BNU-ESM & 2.60 & 1.08 & 0.59 & 0.17 & 0.18 & 0.31 & 0.85 & 0.75 \\
\hline CanESM2 & 2.40 & 0.73 & 0.32 & 0.29 & 0.82 & 0.33 & 0.90 & 0.87 \\
\hline CCSM4 & 1.80 & 0.75 & -0.36 & 0.17 & -0.23 & 0.17 & 1.28 & 0.80 \\
\hline CESM1-BGC & 1.70 & 0.72 & 0.62 & 0.19 & 0.57 & 0.07 & 0.80 & 0.82 \\
\hline CESM1-CAM5 & 2.30 & 1.50 & -0.57 & 0.36 & -0.06 & 0.19 & 1.10 & 0.78 \\
\hline CMCC-CESM & - & 0.59 & -0.45 & 0.77 & 0.73 & 0.16 & 0.86 & 0.76 \\
\hline CMCC-CM & - & 0.55 & 0.12 & 0.29 & -0.12 & 0.29 & 0.45 & 0.72 \\
\hline CMCC-CMS & - & 0.42 & 0.19 & 0.32 & 0.28 & 0.29 & 0.92 & 0.74 \\
\hline CNRM-CM5 & 2.10 & 1.38 & 0.07 & 0.12 & 0.36 & 0.09 & 0.84 & 0.91 \\
\hline CSIRO Mk3.6.0 & 1.80 & 2.14 & 0.42 & 0.58 & -0.14 & 0.49 & 0.05 & 0.68 \\
\hline EC-EARTH & - & 3.04 & 0.51 & 0.05 & 0.08 & 0.17 & 0.64 & 0.88 \\
\hline FIO-ESM & - & 0.89 & 0.18 & 0.16 & 0.01 & 0.09 & 1.15 & 0.91 \\
\hline GFDL CM3 & 2.00 & 1.80 & -0.24 & 0.38 & 0.04 & 0.34 & 0.67 & 0.73 \\
\hline GFDL-ESM2G & 1.10 & 2.03 & -0.09 & 0.26 & 0.19 & 0.47 & 1.62 & 0.72 \\
\hline GFDL-ESM2M & 1.30 & 1.58 & 0.61 & 0.29 & 0.37 & 0.47 & 0.49 & 0.57 \\
\hline GISS-E2-H & 1.70 & 0.64 & -0.21 & 0.36 & 0.10 & 0.27 & 0.73 & 0.88 \\
\hline GISS-E2-H-CC & - & 0.64 & -0.24 & 0.32 & 0.31 & 0.12 & 1.27 & 0.90 \\
\hline GISS-E2-R & 1.50 & 0.57 & -0.37 & 0.29 & 0.53 & 0.07 & 0.83 & 0.90 \\
\hline GISS-E2-R-CC & - & 0.58 & -0.47 & 0.29 & 0.29 & 0.15 & 1.26 & 0.82 \\
\hline HadGEM2-AO & - & 1.27 & 0.10 & 0.24 & 0.46 & 0.50 & 0.94 & 0.78 \\
\hline HadGEM2-CC & - & 1.81 & -1.64 & 0.16 & 0.66 & 0.48 & 1.08 & 0.72 \\
\hline HadGEM2-ES & 2.50 & 1.64 & 0.31 & 0.24 & -0.20 & 0.63 & 0.65 & 0.66 \\
\hline INM-CM4.0 & 1.30 & 1.92 & 0.10 & -0.09 & -0.02 & 0.07 & 0.91 & 0.96 \\
\hline IPSL-CM5A-LR & 2.00 & 2.17 & 0.97 & 0.25 & 0.69 & 0.19 & 0.57 & 0.87 \\
\hline IPSL-CM5A-MR & 2.00 & 1.55 & 0.04 & 0.17 & 0.46 & 0.03 & 1.09 & 0.97 \\
\hline IPSL-CM5B-LR & 1.50 & 1.50 & 0.39 & 0.30 & 0.03 & -0.02 & 0.64 & 1.00 \\
\hline MIROC-ESM & 2.20 & 2.49 & 0.37 & 0.32 & -0.16 & 0.47 & 0.39 & 0.85 \\
\hline MIROC-ESM-CHEM & - & 2.57 & 0.34 & 0.30 & 0.04 & 0.41 & 0.71 & 0.88 \\
\hline MIROC5 & 1.50 & 1.31 & -0.27 & 0.30 & 0.07 & 0.48 & 0.16 & 0.70 \\
\hline MPI-ESM-LR & 2.00 & 1.57 & 0.10 & 0.21 & 0.09 & 0.22 & 1.36 & 0.80 \\
\hline MPI-ESM-MR & 2.00 & 1.34 & 0.61 & 0.26 & 0.44 & 0.15 & 0.93 & 0.82 \\
\hline MRI-CGCM3 & 1.60 & 1.24 & 0.02 & 0.60 & 0.43 & 0.27 & 0.35 & 0.65 \\
\hline NorESM1-M & 1.40 & 1.75 & -0.25 & 0.28 & 0.29 & 0.43 & 0.84 & 0.61 \\
\hline NorESM1-ME & 1.60 & 1.93 & 0.01 & 0.31 & 0.83 & 0.50 & 0.16 & 0.62 \\
\hline
\end{tabular}

provide insights that are not possible from single-model studies or small ensembles.

Here we examine the intermodel spread in the projected surface warming pattern over the tropical Pacific in 38 CMIP5 coupled models and produce indices of surface warming features. We examine the relationships of simple indices of these features to the rainfall projection and explore the possibility of constraining rainfall projections for Pacific island nations based on these indices through emergent constraints.

\section{Data and methods}

We considered outputs from run 1 of 38 models from the CMIP5 archive (Table 1; expansions of the model names are in the appendix), utilizing the historical simulations and simulations under the representative concentration pathway 8.5 (RCP8.5) (Moss et al. 2010), the highest emission scenario included in CMIP5 experiments. We examined surface temperature and precipitation over the tropical Pacific Ocean, $20^{\circ} \mathrm{S}-20^{\circ} \mathrm{N}$ with the major land areas of Central America and Australia excluded, an area encompassing the entire western Pacific warm pool (Fig. 1).

Linear trends in temperature over the periods 1900 2005, 1950-2005, and 2006-2100 were examined. We examined change in near-surface air temperature $(\triangle \mathrm{SAT})$ as a proxy for SST change, as we have access to more models with SAT available. Over the predominantly oceanic tropical Pacific region SAT and SST are very 


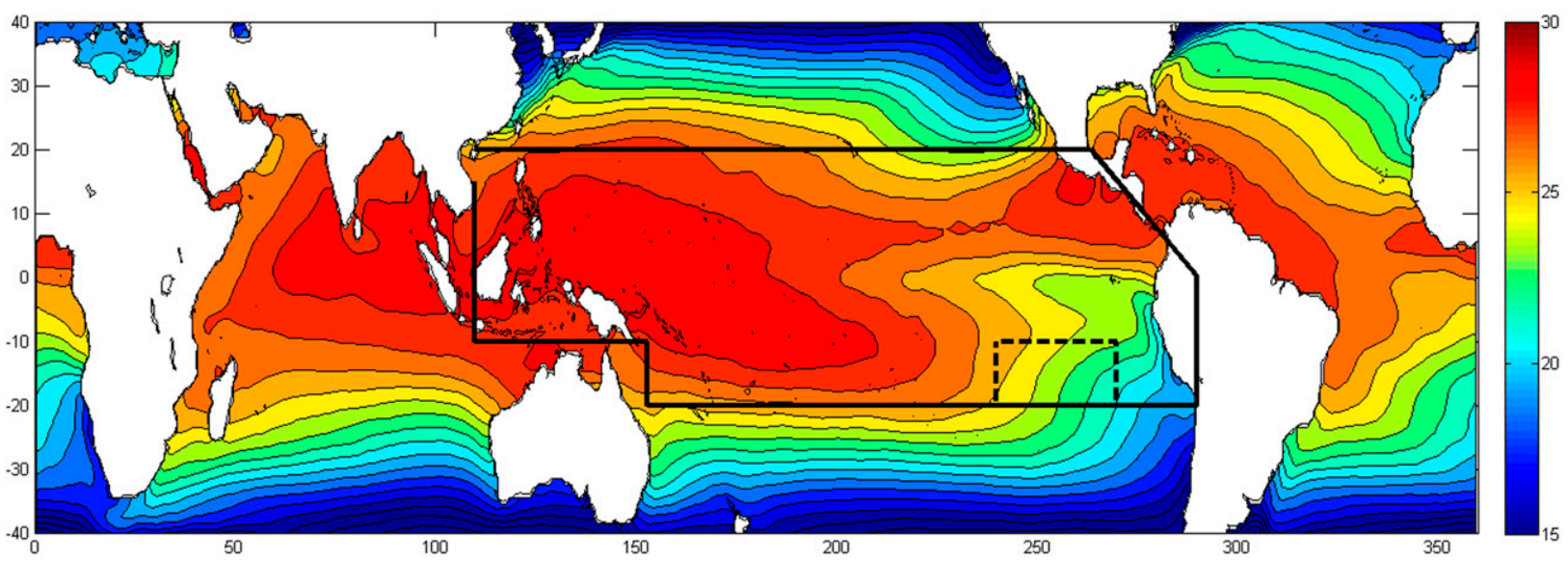

FIG. 1. HadISST mean SST climatology for $1950-99\left({ }^{\circ} \mathrm{C}\right)$ showing the Pacific domain (solid line) and the box to quantify the southeast minimum $\Delta$ SST (dashed line).

similar (the climatology of SST and SAT in models have a correlation of $R>0.96$, and the respective change signals have a correlation of $R>0.91$ over the domain). The multimodel mean projection for the twenty-first century shows a clear EER, hemispheric asymmetry, and southeast minimum warming (Fig. 2a). There is a large range between models in mean warming, and models with the largest warming generally have the largest EER (Fig. 2b). The focus of this study is the spatial patterns of warming independent of the largescale warming rate, so for further analysis the future surface warming responses are normalized by the spatially averaged warming over the domain. Similarly, the future rainfall change is also normalized by mean warming over the domain to show regional patterns and allow for different warming rates. The normalization of the temperature and rainfall changes assumes that spatial surface warming features emerge linearly, and this assumption is evaluated (see below).

The first and second modes of the intermodel empirical orthogonal function (EOF) of the zonalmean normalized $\triangle \mathrm{SAT}$ were examined to establish the most important sources of difference between models. We find the relative contributions to the total variance of $56 \%$ from mode 1 and further $30 \%$ from mode 2 (Fig. 2c), which is similar to those found by Ma and Xie (2013) in CMIP3. The modes derived from this CMIP5 ensemble less clearly separate into the hemispheric asymmetry (mode 1) and an EER (mode 2) found for CMIP3 by Ma and Xie (2013), however they do contain elements of both patterns in each.

To create base functions that best characterize the EER and asymmetry patterns, we use linear combinations of the first two EOFs (Fig. 2d). These linear combinations were derived using a $2 \mathrm{D}$ rotation matrix that maximizes the symmetry about the equator in mode 1 (EER) and maximizes the asymmetry in mode 2 (asymmetry). Using these two base functions we compute indices for each model characterizing the expression of the EER and the asymmetry in the zonal mean warming patterns of individual models for 1950-2005 and 2006-2100 (Table 1) and also 1900-2005. The EER and asymmetry index for each model are defined as the scalar product of zonal mean normalized SAT for that model and the respective base function. A positive EER index thereby characterizes enhanced equatorial warming and a positive asymmetry index refers to the Northern Hemisphere Pacific warming more than the southern.

The relative importance of the southeast minimum across models was quantified by the mean of normalized $\triangle \mathrm{SAT}$ in a box encompassing $10^{\circ}-20^{\circ} \mathrm{S}$ and $90^{\circ}-120^{\circ} \mathrm{W}$ (Fig. 1, Table 1). The hemispheric asymmetry (HA) index and the southeast minimum (SE) index have a correlation of -0.73 , meaning that they are not independent. As such, only the hemispheric asymmetry index is used in further analysis, simplifying analysis to two dimensions. The EER index and the hemispheric asymmetry index are weakly related (correlation of -0.41 ), indicating that the use of linear combinations of EOFs needed to create the distinct patterns results in largely but not entirely independent indices (Fig. 3).

The dependence of each index on mean warming is weak (correlations of $<0.3$ ), indicating that structural differences between models are a larger source of the range in the spatial pattern of normalized warming than the mean warming over the Pacific. This suggests that the assumption behind normalizing the fields is reasonable.

We do not decompose the rainfall signal into dynamic and thermodynamic contributions (Seager et al. 2010), but rather examine the correlation of the normalized rainfall 
a) Projected ensemble mean SAT warming (38 models)

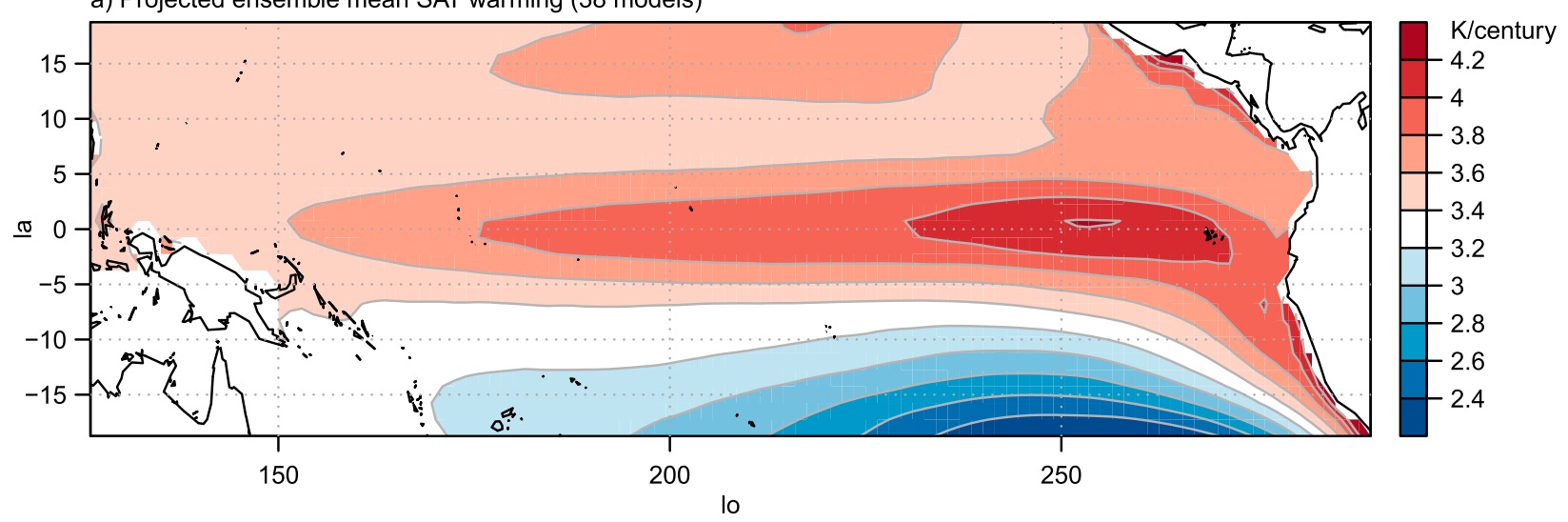

b) Zonally averaged SAT warming

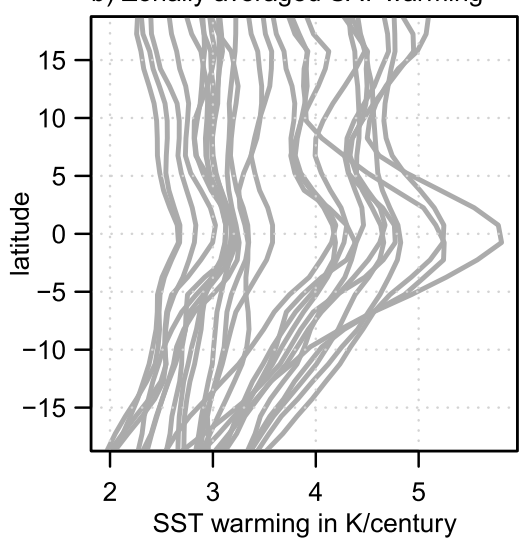

c) First empirical orthogonal functions

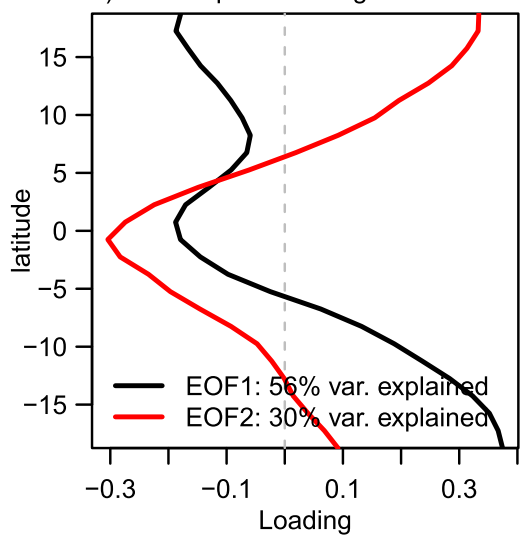

d) Rotated base functions

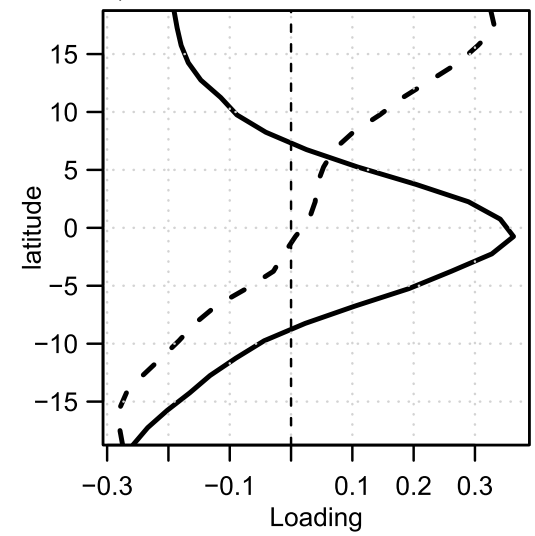

FIG. 2. Projected change in surface temperature in the Pacific Ocean over the twenty-first century (linear trend 2006-2100) under RCP8.5: (a) multimodel mean, (b) zonal average over the domain for 38 CMIP5 models, (c) first and second EOFs of the model range in the zonal average, and (d) linear combination of EOFs used to characterize the EER (solid) and hemispheric asymmetry (dashed).

response to the rainfall climatology and the temperature response. These correlations are taken as a general indication of the relative strength of the wet-get-wetter response and the warmer-get-wetter response respectively.

We compare model mean state and past trends to the Hadley Centre Sea Ice and Sea Surface Temperature dataset version 1.1 (HadISST; Rayner et al. 2003), the Kaplan extended SST version 2 (Kaplanv2; Kaplan et al. 1998), and the National Oceanic and Atmospheric Administration (NOAA) extended reconstructed SST version 3b (ERSSTv3b; Smith et al. 2008). We compare the model precipitation in the current climate to the Climate Prediction Center (CPC) Merged Analysis of Precipitation (CMAP) dataset (Xie and Arkin 1997), noting that there are large differences between observational datasets in the tropical Pacific region (Yin et al. 2004).

\section{Results}

No model has a negative hemispheric asymmetry index, indicating that all models have greater warming in the Northern Hemisphere compared to the southern. One model has a negative EER index (INM-CM4.0), where the equatorial region warms less quickly than other regions. The maximum equatorial warming occurs at different longitudes in different models (see Fig. S1 in the supplemental material), with one model showing the maximum EER in the western Pacific (CSIRO $M k 3.6 .0)$. There are east-west features in the $\triangle \mathrm{SAT}$ pattern in some models that are not captured by the EER and hemispheric asymmetry components, such as an enhanced warming in the northwest region (GFDL-ESM2M, GFDL-ESM2G, NorESM1-M, and NorESM1-ME).

Models with a more pronounced EER tend to have a greater spatial correlation between the temperature response and rainfall response (Fig. 4a), indicating a stronger warmer-get-wetter pattern. The EER score explains $41 \%$ of the variance between models of this spatial correlation in a linear regression framework $(p<$ 0.01 ; Fig. 4a). The correlations between projected warming and projected precipitation response for 


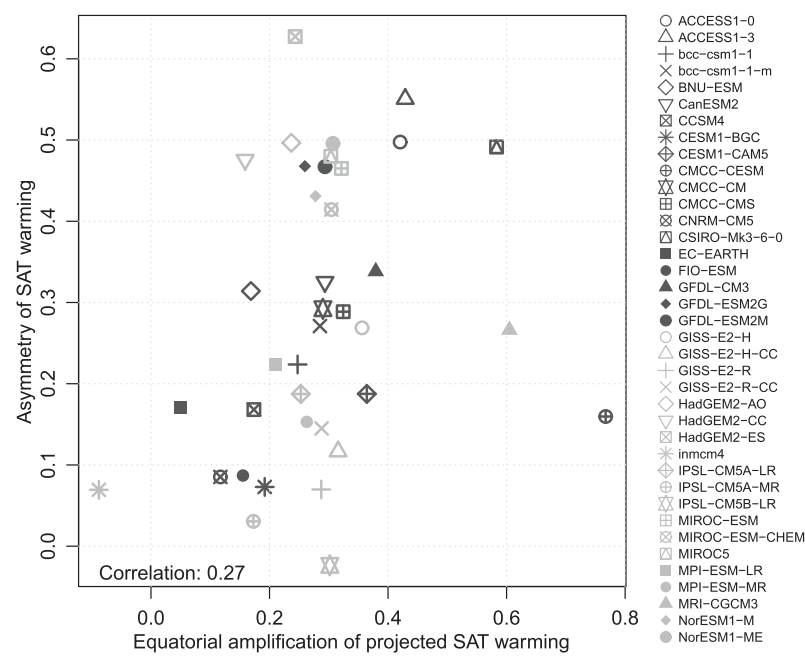

FIG. 3. EER and HA index values in 38 CMIP5 models.

individual models are low $(<0.65)$; however, this is expected because while SST pattern change is the dominant driver of precipitation change in the tropical Pacific, the relationship is nonlinear because of a convective threshold (Johnson and Xie 2010; Chadwick et al. 2014; Watanabe et al. 2014).

In addition, there is a weak $\left(R^{2}=0.23\right)$ but significant $(p<0.01)$ negative linear relationship between the EER index and the correlation of the precipitation response to the rainfall climatology in the current climate (Fig. 4b). This suggests that models with a weak EER exhibit a greater wet-get-wetter-type response. Correlations of the precipitation response to precipitation climatology in the current climate in each model are generally low or in some cases negative, indicating that the wet-get-wetter mechanism is not strong in any model.

In contrast to the EER, there are no statistically significant relationships across the range of models between the hemispheric asymmetry index and the correlation between rainfall response and either the spatial pattern of warming $\left(R^{2}=0.02, p=0.44\right)$ or the rainfall climatology $\left(R^{2}=0.02, p=0.36\right)$. This indicates that the gradients associated with the hemispheric asymmetry do not influence the presence of a warmer-get-wetter response.

Across the range of models, the EER index has a positive relationship to projected rainfall change at the equator and in the northern tropical Pacific (Fig. 5a). That is, models with a higher EER index tend to show a greater increase in rainfall in these regions. The high correlation in the western Pacific is particularly influenced by the outlier CSIRO Mk3.6.0 model, which shows particularly strong warming and rainfall increase there. However, the correlations are similar at the equator and southern tropics even with the six largest
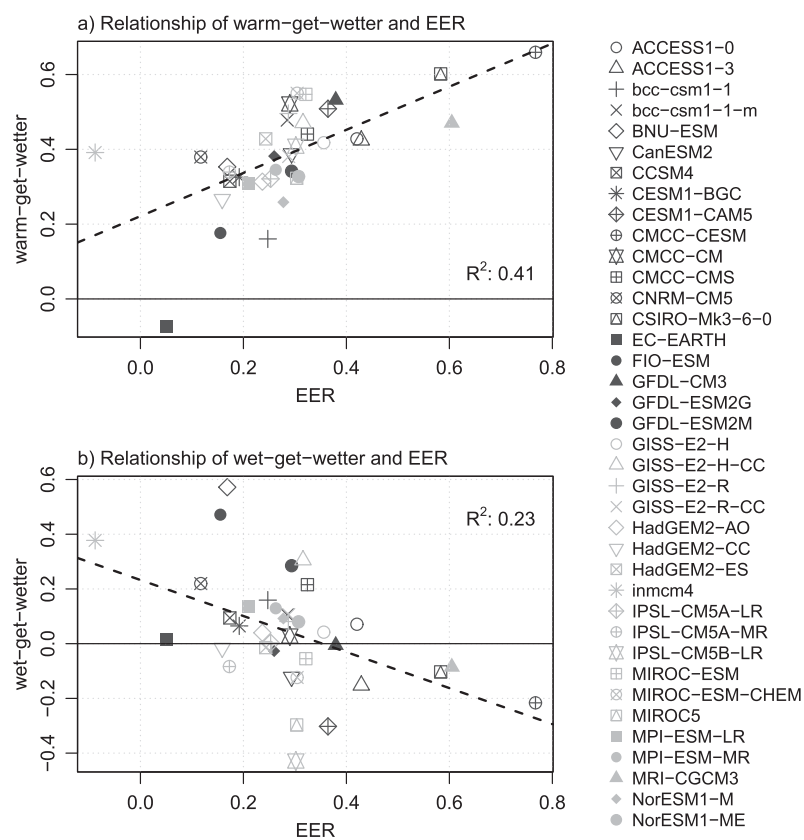

FIG. 4. Relationship between models of the EER index and the (a) warmer-get-wetter and (b) wet-get-wetter responses. The EER index in each CMIP5 model ( $x$ axis) is plotted against the correlation of the total precipitation response and temperature response ( $y$ axis).

outliers removed (not shown). There is also a significant negative relationship of the EER index to the rainfall trend in the South Pacific convergence zone (SPCZ) and the northwest tropical Pacific (Fig. 5a). The asymmetry index has a statistically significant negative relationship to rainfall trend in the south central Pacific, and a positive relationship in some regions of the equator and the northeast (Fig. 5b).

To illustrate the impact of a possible constraint based on these indices, composites of the normalized rainfall response for the 10 models at each end of the range of indices compared to the multimodel mean (Figs. 6 and 7). The multimodel mean rainfall response of CMIP5 shows high model agreement for rainfall increase near the equator but no strong agreement on the sign of change in much of the southern tropics (Fig. 6a). The largest diversions from this mean in each of the composites are in the regions where the relationships are strongest in Fig. 5.

A composite of the 10 models with the lowest EER indices (Fig. 6b) shows lower rainfall increase along the equatorial Pacific and a projected rainfall increase in the SPCZ and northern Australia. This pattern shows a slightly lower dominance of the warmer-get-wetter pattern and so bears some more resemblance to a wetget-wetter response than the multimodel mean. The composite of models with the strongest EER (Fig. 6c) 


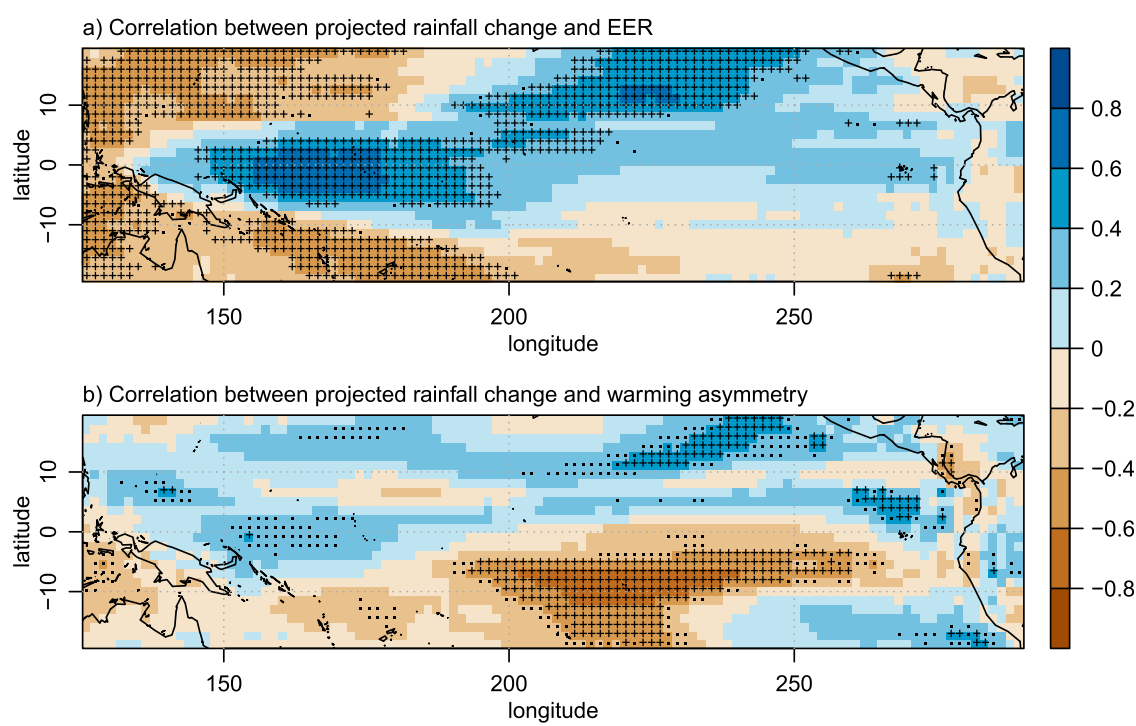

FIG. 5. Correlation between indices and projected rainfall trend across the range of models:

(a) EER index and (b) HA index. Stippling indicates a statistically significant correlation.

shows a greater rainfall decrease across much of the SPCZ and a greater rainfall increase at the equator than the multimodel mean. This composite shows a predominance of the warmer-get-wetter response and minimal wet-get-wetter-type response (also indicated by the models' position in Fig. 4a). Many of the differences between the two composites (Fig. 6d) are very unlikely by chance (assuming the same distribution and

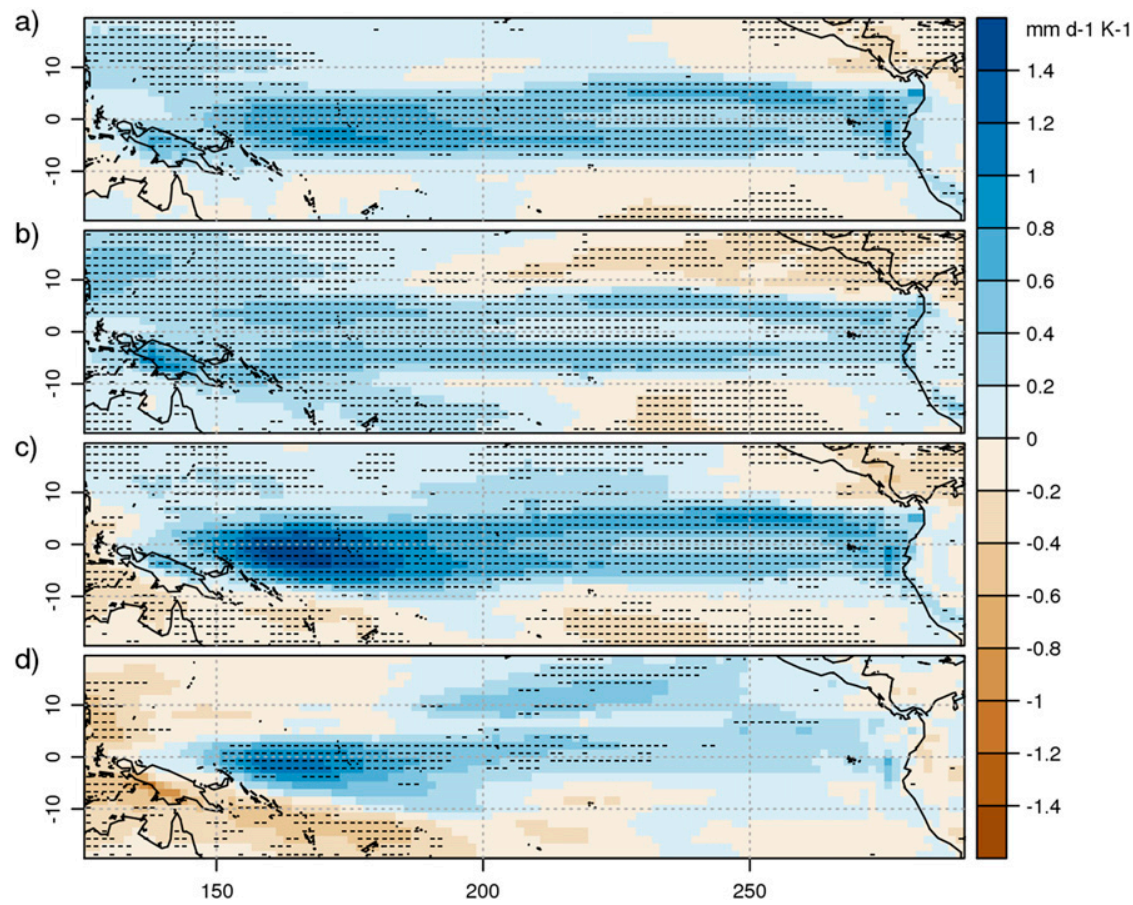

FIG. 6. Composites of the precipitation response (linear trend in 2006-2100, RCP8.5) of (a) 38 CMIP5 models, (b) 10 models with the lowest EER indices, and (c) 10 models with the highest EER indices; stippling indicates where 8 out of 10 models agree on the sign of change. (d) The difference between the composites in (b) and (c); stippling shows where at least 8 out of 10 models in one set are show changes that are larger than the 8th largest model in the other set. 


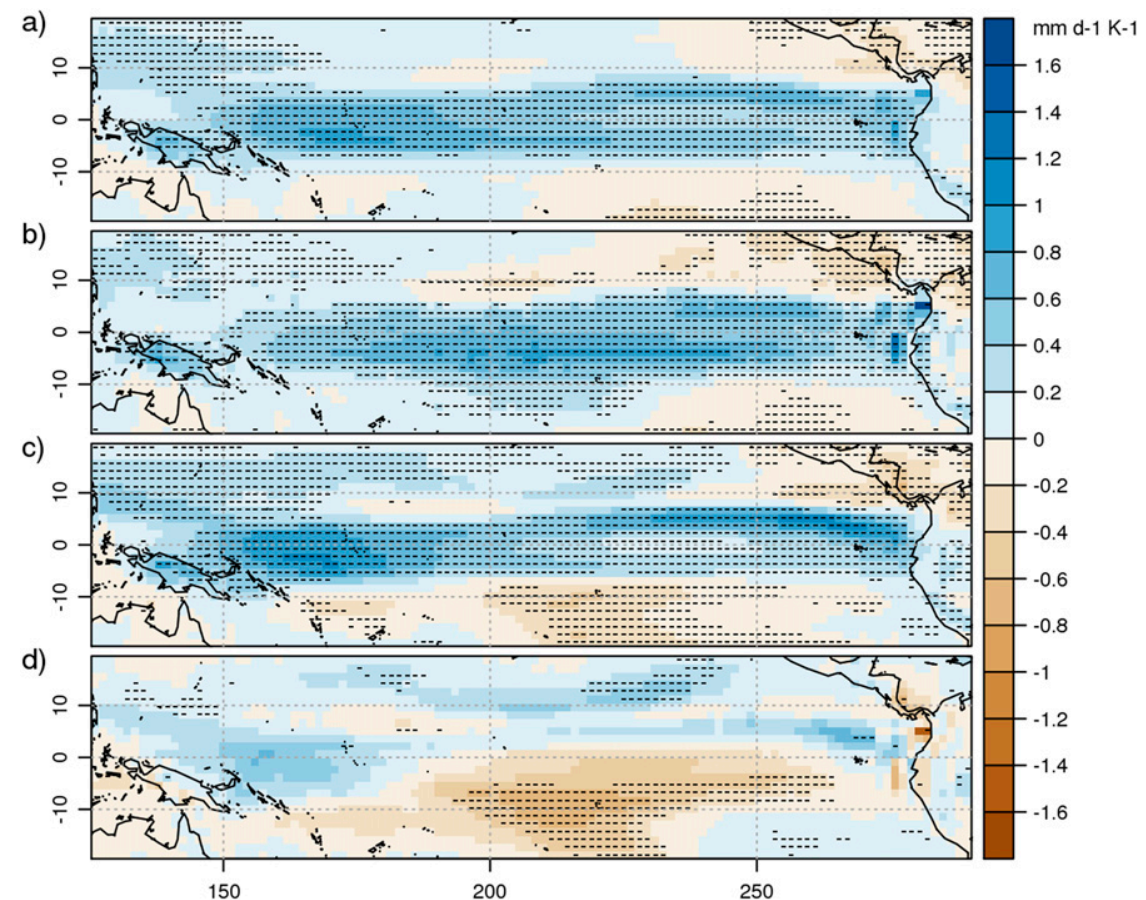

FIG. 7. As in Fig. 6, but for HA indices.

models are independent, stippling would only appear in $\sim 2.5 \%$ of the grid area by chance).

The 10 models with the lowest hemispheric asymmetry show a consistent region of rainfall increase in the southern central tropical Pacific and rainfall decrease in the some parts of the northeastern subtropics (Fig. 7b). In contrast, the 10 models with the highest asymmetry show regions of consistent decrease in the southern subtropics (Fig. 7c). Some of these differences are significant, especially in the central southern Pacific (Fig. 7d). The groups also have a different magnitude of rainfall increase in the western equatorial Pacific.

All model composites show a similar wet-get-wetter seasonal cycle in the zonal mean precipitation response that combines to form the warmer-get-wetter response in annual mean (Fig. 8), consistent with Huang et al. (2013). However, the magnitude of rainfall increase within the tropics and the direction of rainfall change south of $10^{\circ} \mathrm{S}$ differ in each composite. Models with the lowest EER or asymmetry index show a weaker band of rainfall increase and a rainfall increase in the southern tropics throughout the year, whereas models with a strong EER or asymmetry show a greater increase near the equator and a rainfall decrease to the south throughout the year. However, changes south of $10^{\circ} \mathrm{S}$ show no strong model agreement. This disagreement may be related to large model biases in the location of the SPCZ in CMIP5 models (Brown et al. 2013).
None of the three observational SST datasets analyzed shows the development of a distinct EER over the period 1900-2005 (Figs. 9a-c) or over the better sampled period of 1950-2005 (Figs. 9e-g). However, an EER is present over both these periods in the CMIP5 multimodel mean trend in SAT (Figs. 9d,h). However, there are some large differences between observational datasets and the trends in the multimodel mean are not significantly different from all three observed datasets (shown by lack of stippling). Also, there are no clear and consistent asymmetries in trends in the CMIP5 mean in the twentieth century (Figs. 9d,h).

There is no significant relationship between the models' projection of the EER and past trends in the EER index over either the 1900-2005 or 1950-2005 period. This indicates that the sensitivity in this feature in the recent climate does not have a simple relationship to projected change in the EER and other factors may be involved (e.g., recent trends may not be dominated by greenhouse forcing and internal variability may mask the forced signal). There is also no significant correlation between asymmetry in the past trends and asymmetry in future warming.

Furthermore, the projected change in the indices is not significantly related to bias in the zonal mean surface temperature in the current climate. The root-meansquare error (RMSE) of the zonal mean temperature in 1950-2005 compared to HadISST in each model 

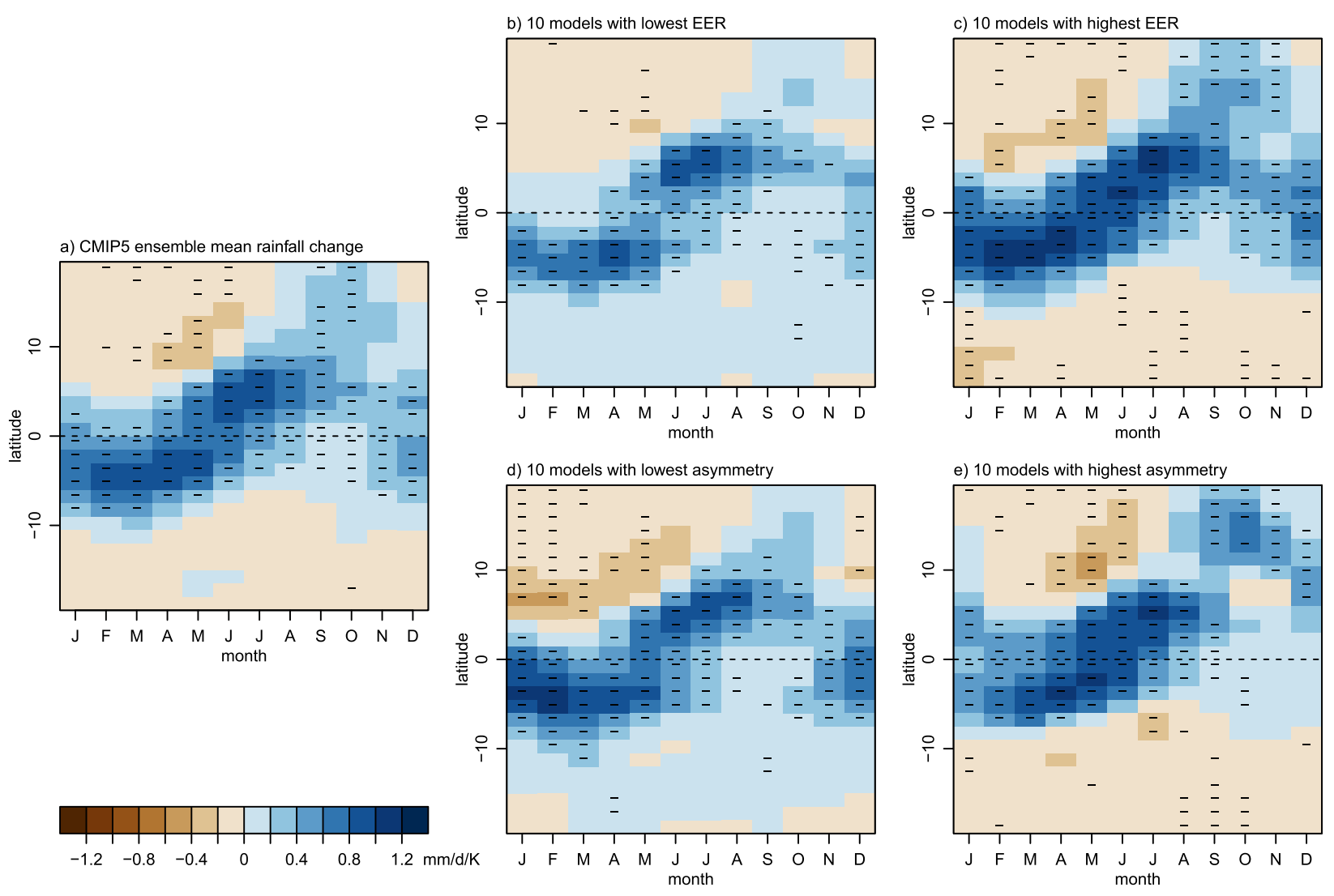

FIG. 8. Seasonal cycle of precipitation response (linear trend in 2006-2100, RCP8.5) zonally averaged across the Pacific domain of (a) the ensemble mean, (b) 10 models with the lowest EER index, (c) 10 models with the highest EER index, (d) 10 models with the lowest asymmetry index, and (e) 10 models with the highest asymmetry index. Stippling shows where 8 out of 10 models agree on the sign of change.

shows no significant correlation to the projected change of the EER (correlations are $<0.2$ ). There is one model where a large bias in current surface temperature is coincident with a large projected change in the western equatorial Pacific, CSIRO Mk3.6.0 (see the supplemental material); however, other models with high RMSE do not have a high EER. This suggests that within the full range of models there is no clear relationship between the bias in this feature of zonal mean SST in the recent climate and projected change, but there may be a relationship for some individual models. Similarly, there is no strong relationship between the RMSE of the zonal mean surface temperature and the projected strength of the hemispheric asymmetry (correlations are $<0.3$ ). The implications of the presence and absence of various relationships described here are further discussed below.

\section{Discussion}

In this study we have examined the effect of two key patterns of change in surface temperature on the precipitation response in the tropical Pacific, focusing on the spread across the CMIP5 ensemble rather than on the multimodel mean. We find that indices of the enhanced equatorial response (EER) in warming, and to a lesser extent the hemispheric asymmetry, are useful in categorizing the range of responses of SST and precipitation across CMIP5 for the tropical Pacific. These indices could be used to constrain regional rainfall projections for Pacific countries, if the more physically plausible projection of the EER and asymmetry can be identified.

\section{a. Wet-get-wetter versus warmer-get-wetter response}

The strength of the EER has an important influence on the dominance of the warmer-get-wetter response in rainfall (Fig. 4). This is expected since an EER contributes to greater SST gradients and greater increased convective mass flux over the equator, leading to an increase in precipitation along the equator (Liu et al. 2005; Xie et al. 2010; Chadwick et al. 2013). The CMIP5 models considered here all have a predominant warmerget-wetter-type response, confirming the finding of 

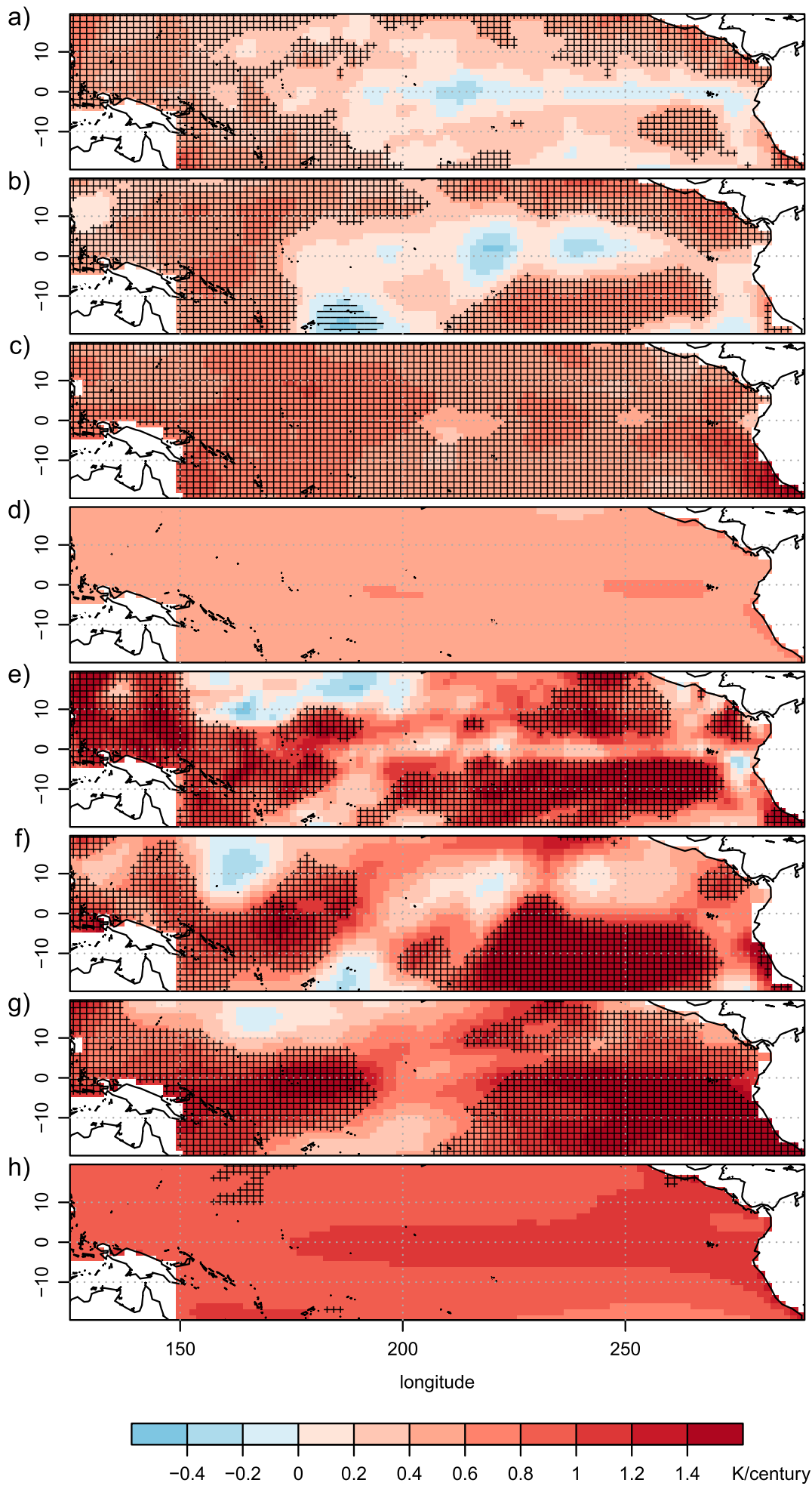

FIG. 9. Linear trend in SST over the tropical Pacific (K century ${ }^{-1}$ ) in 1900-2005 for (a) HadISST, (b) Kaplanv2, (c) NOAA ERSSTv3b, and (d) the CMIP5 multimodel mean; and in 1950-2005 for (e) HadISST, (f) Kaplanv2, (g) NOAA ERSSTv3b, and (h) the CMIP5 multimodel mean. Stippling in observations show trends that are significantly above/below zero, and stippling for CMIP5 multimodel mean indicates where the models are significantly different than all observed datasets. 
Chadwick et al. (2013) that the thermodynamic response is relatively unimportant in determining simulated rainfall changes in the tropical Pacific. However, models with virtually no EER show some presence of a wet-getwetter response (e.g., CNRM-CM5 and CCSM4), compared to those with a strong EER (e.g., MRI-CGCM3). Therefore, constraining the plausible magnitude of the projected EER index is useful for constraining the most likely balance of these two responses.

All model groups examined show the typical band of rainfall increase that varies by season, immediately equatorward of the current precipitation maximum found by Huang et al. (2013). The models with the lowest EER and the weakest asymmetry show a band of rainfall increase that is wider and less sharply delineated than those with high indices (Fig. 8). This is consistent with a weaker anchoring of the rainfall increase to the equator associated with decreased convective mass flux.

\section{b. Regional rainfall projections}

If we were able to reliably restrict projections to either end of the spectrum of the EER index results, this would have fundamental implications for the regional rainfall projections of many Pacific nations. In the subset of 10 models with the lowest EER indices there is a consistently smaller rainfall increase over the equator and rainfall increases in regions within the $10^{\circ}-20^{\circ}$ latitude bands, including in the SPCZ and the northwestern Pacific (Fig. 6b). In contrast, the projection from the 10 models with the highest EER indices (and a greater dominance of the warmer-get-wetter response) shows a marked rainfall increase in the equatorial Pacific, but a decrease in the SPCZ and also in the northwestern Pacific (Fig. 6c). For nations in the SPCZ such as Vanuatu, Fiji, Tonga, and Niue, and also for East Timor, this represents a difference in the sign of the projected mean rainfall change from an increase to a decrease. Similarly, for nations along the equator such as Nauru and Kiribati, this represents a difference between a moderate increase in mean rainfall and a large increase.

A constraint to either end of the spectrum of hemispheric asymmetry index results has implications for the regional rainfall projection in some regions of the central southern tropical Pacific such as French Polynesia. A low asymmetry implies a rainfall increase in the southern central Pacific (Fig. 7b) whereas a high asymmetry implies a stronger rainfall increase in the equatorial western Pacific and a rainfall decrease in the southern Pacific (Fig. 7c).

\section{c. Prospects for constraining projections}

The EER in particular explains a significant proportion of the spread in rainfall response across models in the western Pacific. If it is possible to identify the most plausible and physically consistent projection of this feature, then it may be possible to constrain the range of the CMIP5 rainfall projections for the Pacific island nations. This constraint could be applied by weighting or rejecting models according to their EER score, or otherwise adjusting the projection distribution.

A distinct EER developed over the twentieth century in CMIP5 historical simulations, but not in any observational datasets examined here (Fig. 9). This suggests that models with a strong EER may not have a realistic simulation of SST trends at centennial scales. Further evidence that many models may not simulate internal variability or forced responses realistically at these time scales in this region comes from differences in the decadal to centennial variability in the Niño-3.4 index between CMIP5 millennial simulations and paleoclimate reconstructions (Ault et al. 2013). However, there are two complicating factors. First, centennial-scale trends in SST in the equatorial Pacific in the early part of the record are uncertain due to a lack of observations early in the twentieth century (Deser et al. 2010), and over shorter time scales the aliasing of large multidecadal variability can produce SST trends that are unrelated to external forcing. This makes the comparison of models and observations problematic in regards to this question. Recent work found that some enhanced warming over the equator may be present in 1950-2009 when examining dataset based only on bucket measurements (Tokinaga et al. 2012). Second, in CMIP5 there is no significant correlation between the past trends and future trends in the EER. This means that past trends in EER cannot be used with confidence in a simple emergent constraint framework.

Bias in the current climate is also a potential factor to help constrain projections. A large equatorial cold tongue bias in the western Pacific in the current climate is likely to affect the potential for equatorial warming. For example, the CSIRO Mk3.6.0 model has a particularly marked cold tongue bias located in the western Pacific (see the supplemental material) and shows a correspondingly large increase in surface temperature in the same region. In this case, the particularly strong EER response is influenced by bias in the current climate. Further, it has been shown more generally that warming to the east of the western Pacific warm pool is greater in models with a greater bias in the shape of the edge of the warm pool (Brown et al. 2014; Brown et al. 2014, manuscript submitted to Deep-Sea Res.). However, we find no significant relationship across full range of models between bias in the zonal mean surface temperature and the projection of the EER. That is, a very strong bias may have an effect on projections, but there is not 
a relationship across the range of bias. Also, this study used only zonal means, but the east-west dimension appears to be important. This suggests that the strength of the cold tongue bias may be used as a basis to reject models but not as a constraint across the whole range.

While there is no simple emergent constraint linking either past trends or biases in surface temperature to EER, a constraint may be found by looking at the contributing processes. Because we are attempting to constraint based on a single climate feature, it is possible to look at the physical processes and feedbacks involved in that feature. In this case, the exact balance of upwelling damping, thermocline feedback, zonal advection and evaporative damping that contribute to the EER (Xie et al. 2010) is of interest. However, determining the most plausible balance of processes is complicated by fundamental uncertainties with modeling convective processes in the tropics in all models, which can be illustrated by looking at simpler model runs. In aquaplanet simulations with prescribed surface temperature warming, there is a wide range of cloud and precipitation response in the tropics, ranging from a very distinct to a much less distinct peak at the equator (Medeiros et al. 2008). This reflects the uncertainties in the coupling of water and circulation that depend on finescale processes such as moist convection and cloud formation that must be parameterized (Möbis and Stevens 2012; Stevens and Bony 2013). Further model complexity in fully coupled ocean-atmosphere models only add further uncertainty to climate simulations. Therefore, we suggest that an analysis of the fundamental representation of processes such as convection and cloud formation is needed to confidently assess what is the most plausible magnitude of the EER.

\section{d. Wider application}

Since spatial patterns of warming in the Pacific have farreaching impacts (e.g., Kosaka and Xie 2013), such a constraint would have wider impact for global projections. For example, in the models with the highest EER score (and also asymmetry), there is a decline in mean annual rainfall in some regions of Australia. This may be linked to the teleconnection between the Pacific and Indian Ocean temperatures and rainfall projections for Australia in CMIP3 described by the Pacific-Indian Ocean dipole index of $\Delta$ SST by Watterson (2012). That study found that the higher warming in the equatorial Pacific to the northeast of Australia is associated with the driest rainfall projections for Australia. So a framework to constrain projections based on these two features may also be applicable in regions other than the western Pacific.

The multimodel mean projection is often used to represent the best estimate of projections (e.g., Collins et al. 2013; IPCC 2013), and this model mean contains a strong EER in both surface temperature and rainfall and assigned high confidence based on high model agreement. However, if the model range could confidently be constrained to the lower end of the EER or asymmetry range, the multimodel mean would not be a good representation of the most likely change.

\section{Conclusions}

A simple index of the enhanced equatorial response (EER) and to a lesser extent and index of the hemispheric asymmetry in projected surface warming of the Pacific provide a useful framework for categorizing rainfall projections in CMIP5. Groups of models at each end of the range in these indices show important differences in precipitation response compared to the multimodel mean projection in many regions, including along the equator and in the convergence zones. Moreover, models with stronger EER have a greater dominance of dynamically forced rainfall changes and a warmer-get-wetter response. Thus, constraining the most plausible intensity of the enhanced equatorial warming over the twenty-first century using these indices would provide a constraint on regional rainfall projections and on the dominance of the warmer-getwetter response. This in turn would be very valuable for the use of projections in climate change planning and adaptation work. While we find no simple emergent constraint in past trends or in model bias, a deeper look at model processes and feedbacks could provide this useful outcome.

Acknowledgments. This research was conducted with the support of the Pacific-Australia Climate Change Science and Adaptation Planning Program funded by AusAID in collaboration with the Department of Climate Change and Energy Efficiency, and delivered by the Bureau of Meteorology and the Commonwealth Scientific and Industrial Research Organisation (CSIRO). We thank the PCMDI and the World Climate Research Program's Working Group on Coupled Modelling for their roles in making available the CMIP3 and CMIP5 multimodel datasets. Support of this dataset is provided by the Office of Science, U.S. Department of Energy. More details on model documentation are available at the PCMDI website (http:// www-pcmdi.llnl.gov/). The authors also thank the data processing team at CSIRO for the CMIP5 and observed data access. We also thank Jaci Brown and Robert Colman for comments and suggestions on the development of the paper. 


\section{APPENDIX}

\section{Expansions for CMIP5 Models Listed in Table 1}

\section{ACCESS1.0 \\ ACCESS1.3 \\ BCC_CSM1.1 \\ BCC_CSM1.1 \\ (m)}

BNU-ESM

CanESM2

CCSM4

CESM1-BGC

CESM1-

CAM5

CMCC-CESM

CMCC-CM

CMCC-CMS

CNRM-CM5

CSIRO

Mk3.6.0

EC-EARTH

FIO-ESM

GFDL CM3

GFDLESM2G

GFDLESM2M
Australian Community Climate and Earth System Simulator, version 1.0 Australian Community Climate and Earth System Simulator, version 1.0 Beijing Climate Center, Climate System Model, version 1.1

Beijing Climate Center, Climate System Model, version 1.1 (moderate resolution)

Beijing Normal University-Earth System Model

Second Generation Canadian Earth System Model

Community Climate System Model, version 4

Community Earth System Model, version 1-Biogeochemical

Community Earth System Model, version 1 (Community Atmosphere Model, version 5)

Centro Euro-Mediterraneo sui Cambiamenti Climatici Carbon Cycle Earth System Model

Centro Euro-Mediterraneo sui Cambiamenti Climatici Climate Model

Centro Euro-Mediterraneo sui Cambiamenti Climatici Climate Model with a resolved stratosphere

Centre National de Recherches Météorologiques Coupled Global Climate Model, version 5

Commonwealth Scientific and Industrial Research Organisation Mark 3.6.0

EC-Earth Consortium Earth System Model

First Institute of Oceanography Earth System Model

Geophysical Fluid Dynamics Laboratory Climate Model, version 3

Geophysical Fluid Dynamics Laboratory Earth System Model with Generalized Ocean Layer Dynamics (GOLD) component

Geophysical Fluid Dynamics Laboratory Earth System Model with Modular Ocean Model 4 (MOM4) component
GISS-E2-H

GISS-E2-H-

$\mathrm{CC}$

GISS-E2-R

GISS-E2-R$\mathrm{CC}$
HadGEM2- $\mathrm{AO}$

HadGEM2-

$\mathrm{CC}$

HadGEM2-ES

INM-CM4.0 IPSL-CM5A-
LR

IPSL-CM5AMR

IPSL-CM5BLR

MIROC-ESM

MIROC-ESMCHEM

MIROC5

MPI-ESM-LR

MPI-ESMMR

MRI-CGCM3

NorESM1-M

NorESM1-ME
Goddard Institute for Space Studies Model E2, coupled with the Hybrid Coordinate Ocean Model (HYCOM)

Goddard Institute for Space Studies Model E2, coupled with HYCOM and interactive terrestrial carbon cycle

Goddard Institute for Space Studies Model E2, coupled with the Russell ocean model

Goddard Institute for Space Studies Model E2, coupled with the Russell ocean model and interactive terrestrial carbon cycle

Hadley Centre Global Environment Model, version 2-Atmosphere and Ocean

Hadley Centre Global Environment Model, version 2-Carbon Cycle

Hadley Centre Global Environment Model, version 2-Earth System

Institute of Numerical Mathematics Coupled Model, version 4.0

L'Institut Pierre-Simon Laplace Coupled Model, version 5A, low resolution

L'Institut Pierre-Simon Laplace Coupled Model, version 5A, mid resolution

L'Institut Pierre-Simon Laplace Coupled Model, version 5B, low resolution

Model for Interdisciplinary Research on Climate, Earth System Model

Model for Interdisciplinary Research on Climate, Earth System Model, Chemistry Coupled

Model for Interdisciplinary Research on Climate, version 5

Max Planck Institute Earth System Model, low resolution

Max Planck Institute Earth System Model, medium resolution

Meteorological Research Institute Coupled Atmosphere-Ocean General Circulation Model, version 3

Norwegian Earth System Model, version 1 (intermediate resolution)

Norwegian Earth System Model, version 1 (intermediate resolution) with carbon cycling 


\section{REFERENCES}

Ault, T. R., C. Deser, M. Newman, and J. Emile-Geay, 2013: Characterizing decadal to centennial variability in the equatorial Pacific during the last millennium. Geophys. Res. Lett., 40, 3450-3456, doi:10.1002/grl.50647.

Brown, J. N., C. Langlais, and C. Maes, 2014: Zonal structure and variability of the western Pacific dynamic warm pool edge in CMIP5. Climate Dyn., 42, 3061-3076, doi:10.1007/ s00382-013-1931-5.

Brown, J. R., A. F. Moise, and F. P. Delage, 2012: Changes in the South Pacific convergence zone in IPCC AR4 future climate projections. Climate Dyn., 39, 1-19, doi:10.1007/ s00382-011-1192-0.

_, _, and R. Colman, 2013: The South Pacific convergence zone in CMIP5 simulations of historical and future climate. Climate Dyn., 41, 2179-2197, doi:10.1007/s00382-012-1591-x.

Cai, W., and P. H. Whetton, 2000: Evidence for a time-varying pattern of greenhouse warming in the Pacific Ocean. Geophys. Res. Lett., 27, 2577-2580, doi:10.1029/1999GL011253.

Chadwick, R., I. Boutle, and G. Martin, 2013: Spatial patterns of precipitation change in CMIP5: Why the rich do not get richer in the tropics. J. Climate, 26, 3803-3822, doi:10.1175/ JCLI-D-12-00543.1.

_ , P. Good, T. Andrews, and G. Martin, 2014: Surface warming patterns drive tropical rainfall pattern responses to $\mathrm{CO}_{2}$ forcing on all timescales. Geophys. Res. Lett., 41, 610-615, doi:10.1002/2013GL058504.

Chou, C., J. D. Neelin, C.-A. Chen, and J.-Y. Tu, 2009: Evaluating the "rich-get-richer" mechanism in tropical precipitation change under global warming. J. Climate, 22, 1982-2005, doi:10.1175/2008JCLI2471.1.

Clement, A. C., R. Seager, M. A. Cane, and S. E. Zebiak, 1996: An ocean dynamical thermostat. J. Climate, 9, 2190-2196, doi:10.1175/1520-0442(1996)009<2190:AODT>2.0.CO;2.

Collins, M., and Coauthors, 2013: Long-term climate change: Projections, commitments and irreversibility. Climate Change 2013: The Physical Science Basis, T. F. Stocker et al., Eds., Cambridge University Press, 1029-1136.

Deser, C., A. S. Phillips, and M. A. Alexander, 2010: Twentieth century tropical sea surface temperature trends revisited. Geophys. Res. Lett., 37, L10701, doi:10.1029/ 2010GL043321.

DiNezio, P. N., A. C. Clement, G. A. Vecchi, B. J. Soden, B. P. Kirtman, and S.-K. Lee, 2009: Climate response of the equatorial Pacific to global warming. J. Climate, 22, 4873-4892, doi:10.1175/2009JCLI2982.1.

England, M. H., and Coauthors, 2014: Recent intensification of wind-driven circulation in the Pacific and the ongoing warming hiatus. Nat. Climate Change, 4, 222-227, doi:10.1038/ nclimate2106.

Flato, G. M., and Coauthors, 2013: Evaluation of climate models. Climate Change 2013: The Physical Science Basis, T. F. Stocker et al., Eds., Cambridge University Press, 741866.

Grose, M. R., and Coauthors, 2014: Assessment of the CMIP5 global climate model simulations of the western tropical Pacific climate system and comparison to CMIP3. Int. J. Climatol., 34, 3382-3399, doi:10.1002/joc.3916.

Hall, A., and X. Qu, 2006: Using the current seasonal cycle to constrain snow albedo feedback in future climate change. Geophys. Res. Lett., 33, L03502, doi:10.1029/ 2005 GL025127.
Held, I. M., and B. J. Soden, 2006: Robust responses of the hydrological cycle to global warming. J. Climate, 19, 5686-5699, doi:10.1175/JCLI3990.1.

Huang, P., S.-P. Xie, K. Hu, G. Huang, and R. Huang, 2013: Patterns of the seasonal response of tropical rainfall to global warming. Nat. Geosci., 6, 357-361, doi:10.1038/ngeo1792.

IPCC, 2013: Annex I: Atlas of global and regional climate projections. Climate Change 2013: The Physical Science Basis, T. F. Stocker et al., Eds., Cambridge University Press, 1311-1394.

Johnson, N. C., and S.-P. Xie, 2010: Changes in the sea surface temperature threshold for tropical convection. Nat. Geosci., $\mathbf{3}$, 842-845, doi:10.1038/ngeo1008.

Jun, M., R. Knutti, and D. W. Nychka, 2008: Spatial analysis to quantify numerical model bias and dependence: How many climate models are there? J. Amer. Stat. Assoc., 103, 934-947, doi:10.1198/016214507000001265.

Kaplan, A., M. A. Cane, Y. Kushnir, A. C. Clement, M. B. Blumenthal, and B. Rajagopalan, 1998: Analyses of global sea surface temperature 1856-1991. J. Geophys. Res., 103 (C9), 1856718 589, doi:10.1029/97JC01736.

Kosaka, Y., and S.-P. Xie, 2013: Recent global-warming hiatus tied to equatorial Pacific surface cooling. Nature, 501, 403-407, doi:10.1038/nature12534.

Li, G., and S.-P. Xie, 2013: Tropical biases in the CMIP5 multimodel ensemble: The excessive equatorial Pacific cold tongue and double ITCZ problems. J. Climate, 27, 1765-1780, doi:10.1175/JCLI-D-13-00337.1.

Liu, Z., 1998: The role of ocean in the response of tropical climatology to global warming: The west-east SST contrast. J. Climate, 11, 864-875, doi:10.1175/1520-0442(1998)011<0864: TROOIT $>2.0 . \mathrm{CO} ; 2$.

— S. Vavrus, F. He, N. Wen, and Y. Zhong, 2005: Rethinking tropical ocean response to global warming: The enhanced equatorial warming. J. Climate, 18, 4684-4700, doi:10.1175/ JCLI3579.1.

Ma, J., and S.-P. Xie, 2013: Regional patterns of sea surface temperature change: A source of uncertainty in future projections of precipitation and atmospheric circulation. J. Climate, 26, 2482-2501, doi:10.1175/JCLI-D-12-00283.1.

Masson, D., and R. Knutti, 2011: Spatial-scale dependence of climate model performance in the CMIP3 ensemble. J. Climate, 24, 2680-2692, doi:10.1175/2011JCLI3513.1.

Medeiros, B., B. Stevens, I. M. Held, M. Zhao, D. L. Williamson, J. G. Olson, and C. S. Bretherton, 2008: Aquaplanets, climate sensitivity, and low clouds. J. Climate, 21, 4974-4991, doi:10.1175/2008JCLI1995.1.

Meehl, G. A., and H. Teng, 2012: Case studies for initialized decadal hindcasts and predictions for the Pacific region. Geophys. Res. Lett., 39, L22705, doi:10.1029/2012GL053423.

Möbis, B., and B. Stevens, 2012: Factors controlling the position of the intertropical convergence zone on an aquaplanet. $J . A d v$. Model. Earth Syst., 4, M00A04, doi:10.1029/2012MS000199.

Moss, R. H., and Coauthors, 2010: The next generation of scenarios for climate change research and assessment. Nature, 463, 747756, doi:10.1038/nature08823.

Rayner, N. A., D. E. Parker, E. B. Horton, C. K. Folland, L. V. Alexander, D. P. Rowell, E. C. Kent, and A. Kaplan, 2003: Global analyses of sea surface temperature, sea ice, and night marine air temperature since the late nineteenth century. J. Geophys. Res., 108, 4407, doi:10.1029/2002JD002670.

Reifen, C., and R. Toumi, 2009: Climate projections: Past performance no guarantee of future skill? Geophys. Res. Lett., 36, L13704, doi:10.1029/2009GL038082. 
Schaller, N., I. Mahlstein, J. Cermak, and R. Knutti, 2011: Analyzing precipitation projections: A comparison of different approaches to climate model evaluation. J. Geophys. Res., 116, D10118, doi:10.1029/2010JD014963.

Seager, R., N. Naik, and G. A. Vecchi, 2010: Thermodynamic and dynamic mechanisms for large-scale changes in the hydrological cycle in response to global warming. J. Climate, 23, 4651-4668, doi:10.1175/2010JCLI3655.1.

Smith, T. M., R. W. Reynolds, T. C. Peterson, and J. Lawrimore, 2008: Improvements to NOAA's Historical Merged LandOcean Surface Temperature Analysis (1880-2006). J. Climate, 21, 2283-2296, doi:10.1175/2007JCLI2100.1.

Sobel, A. H., and S. J. Camargo, 2011: Projected future seasonal changes in tropical summer climate. J. Climate, 24, 473-487, doi:10.1175/2010JCLI3748.1.

Stevens, B., and S. Bony, 2013: What are climate models missing? Science, 340, 1053-1054, doi:10.1126/science.1237554.

Taylor, K. E., R. J. Stouffer, and G. A. Meehl, 2012: An overview of CMIP5 and the experiment design. Bull. Amer. Meteor. Soc., 93, 485-498, doi:10.1175/BAMS-D-11-00094.1.

Timmermann, A., S. McGregor, and F.-F. Jin, 2010: Wind effects on past and future regional sea level trends in the southern IndoPacific. J. Climate, 23, 4429-4437, doi:10.1175/2010JCLI3519.1.

Tokinaga, H., S.-P. Xie, C. Deser, Y. Kosaka, and Y. M. Okumura, 2012: Slowdown of the Walker circulation driven by tropical Indo-Pacific warming. Nature, 491, 439-443, doi:10.1038/ nature11576.

Vecchi, G. A., and B. J. Soden, 2007: Global warming and the weakening of the tropical circulation. J. Climate, 20, 43164340, doi:10.1175/JCLI4258.1.

, - - A. T. Wittenberg, I. M. Held, A. Leetmaa, and M. J. Harrison, 2006: Weakening of tropical Pacific atmospheric circulation due to anthropogenic forcing. Nature, 441, 73-76, doi:10.1038/nature04744.
Watanabe, M., Y. Kamae, and M. Kimoto, 2014: Robust increase of the equatorial Pacific rainfall and its variability in a warmed climate. Geophys. Res. Lett., 41, 3227-3232, doi:10.1002/ 2014 GL059692.

Watterson, I., 2012: Understanding and partitioning future climates for Australian regions from CMIP3 using ocean warming indices. Climatic Change, 111, 903-922, doi:10.1007/ s10584-011-0166-x.

Whetton, P. H., I. Macadam, J. Bathols, and J. O'Grady, 2007: Assessment of the use of current climate patterns to evaluate regional enhanced greenhouse response patterns of climate models. Geophys. Res. Lett., 34, L14701, doi:10.1029/ 2007GL030025.

Widlansky, M. J., A. Timmermann, K. Stein, S. McGregor, N. Schneider, M. H. England, M. Lengaigne, and W. Cai, 2013: Changes in South Pacific rainfall bands in a warming climate. Nat. Climate Change, 3, 417-423, doi:10.1038/nclimate1726.

Xie, P., and P. A. Arkin, 1997: Global precipitation: A 17-year monthly analysis based on gauge observations, satellite estimates, and numerical model outputs. Bull. Amer. Meteor. Soc., 78, 2539-2558, doi:10.1175/1520-0477(1997)078<2539: GPAYMA $>2.0 . \mathrm{CO} ; 2$.

Xie, S.-P., C. Deser, G. A. Vecchi, J. Ma, H. Teng, and A. T. Wittenberg, 2010: Global warming pattern formation: Sea surface temperature and rainfall. J. Climate, 23, 966-986, doi:10.1175/2009JCLI3329.1.

Yin, X., A. Gruber, and P. A. Arkin, 2004: Comparison of the GPCP and CMAP merged gauge-satellite monthly precipitation products for the period 1979-2001. J. Hydrometeor., 5, 1207-1222, doi:10.1175/JHM-392.1.

Zheng, Y., J.-L. Lin, and T. Shinoda, 2012: The equatorial Pacific cold tongue simulated by IPCC AR4 coupled GCMs: Upper ocean heat budget and feedback analysis. J. Geophys. Res., 117C, C05024, doi:10.1029/2011JC007746. 